\title{
Efficacy of indigenous entomopathogenic fungus, Beauveria bassiana (Balsamo) Vuillemin, isolates against the rose aphid, Macrosiphum rosae L. (Hemiptera: Aphididae) in rose production
}

\author{
Samy Mahmoud Sayed ${ }^{1,2^{*}}$, Esmat Farouk Ali $^{2}$ and Saqer Sultan Al-Otaibi ${ }^{2}$
}

\begin{abstract}
The rose aphid, Macrosiphum rosae L. (Hemiptera: Aphididae), is an important insect pest of rose plants because it damages the leaves and flowers. The entomopathogenic fungus, Beauveria bassiana Balsamo (Vuillemin), is environmentally safe in comparison with the chemical pesticides. The indigenous fungal isolates can be the best options in biological control because they are more adapted to the local environment. In the present study, four genetically different isolates of $B$. bassiana (isolates $1,2,3$, and 4) were used to estimate $L C_{50}$ for the rose aphid. Also, the same isolates were used to control the aphid's infestation on rose plants in the field, and the efficacy was compared with a commercial strain $\left(\right.$ Naturalis $\left.{ }^{\oplus}\right)$ with two concentrations for each isolate $\left(2.3 \times 10^{6}\right.$ and $4.6 \times 10^{6}$ conidia/ml). Bioassay results indicated that isolate 1 differed significantly $\left(L C_{50}=6.46 \times 10^{4}\right)$ than the other three ones $\left(\mathrm{LC}_{50}=1.46 \times 10^{5}, 1.52 \times 10^{5}\right.$, and $\left.1.71 \times 10^{5}\right)$. In field trials, the concentration of $4.6 \times 10^{6} \mathrm{conidia} / \mathrm{ml}$, for indigenous as well as commercial strains, achieved the highest reductions of rose aphid infestation and the highest extraction of rose oil. Thus, this fungus can be recommended in organic rose production. Further investigations are needed for the improvement in utilization of these isolates with regard to UV radiations in the field.
\end{abstract}

Keywords: Macrosiphum rosae, Biological control, Beauveria bassiana isolates, Rosa damascena

\section{Background}

Rose plant, Rosa damascena trigintipetala Mill., is cultivated in Taif, Saudi Arabia, where a special local variety called Taify rose is well known for its oil contents and its suitability for growth under local climate. Rose plants are infested by many insect pests especially rose aphids, thrips, whiteflies, and some lepidopteran larvae. These insect pests cause high damages to rose plants especially to buds, leaves, and flowers. Therefore, the rose yields are reduced by infestations with these insect pests (Karlik and Tjosvold 2003).

Rose aphid, Macrosiphum rosae L. (Hemiptera: Aphididae); green peach aphid, Myzus persicae; cotton aphid, Aphis gossypii Glov.; and potato aphid, Macrosiphum

\footnotetext{
*Correspondence: samy_mahmoud@hotmail.com

'Department of Economic Entomology and Pesticides, Faculty of Agriculture, Cairo University, Giza 12613, Egypt

${ }^{2}$ Faculty of Science, Taif University, Taif 888, Saudi Arabia
}

euphorbiae (Thomas), are the important aphid pest species that infest and damage rose plants (Karlik and Tjosvold 2003). M. rosae also attacks the photinia, pyracantha, and many of fruit trees, which are closely related to rose plants. Aphid infestation deformed leaves and new bloom stems and also is considered as a vector of several plant viruses that impact rose plants (Chau and Heinz 2004). The infestation of aphids on rose plants may affect the composition of plant biochemicals (Singh et al. 2014). Sayed and Montaser (2012) and Sayed and Alghamdi (2017) reported high infestations with $M$. rosae on Taif's rose.

Entomopathogenic fungus (EPF), Beauveria bassiana Balsamo (Vuillemin), can be one of the best bio-control agents of the rose aphid. There is an increasing interest in utilization and mass propagation of EPF for controlling insect pests (Inglis et al. 2001). B. bassiana is the causing 
agent of the white muscardine disease of various insect species (Tanada and Kaya 1993) that causes epizootics under various climatic conditions among field and soilborne insect pests. This fungus represents the first example describing a microorganism as the bio-agent of a contagious disease and contains various genotypes and probably comprises a complex of many species. Consequently, it is thinkable to find individual isolates or pathotypes which represent a substantially restricted host range (Inglis et al. 2001).

Many of EPF are being developed for controlling a large number of agricultural pests and some of them such as B. bassiana and Metarhizium anisopliae (Metschnikoff) Sorokin are already available as commercial products for controlling various pest species (Amatuzzi et al. 2017). Moreover, EPF can be used in combination with the parasitoids and predators, as biological control agents, for controlling the aphids. This method requires an effective time management in order to prevent the antagonistic interactions (Martins et al. 2014 and Seiedy et al. 2015).

The isolation of indigenous isolates or strains of EPF from different hosts and locations provides a control program with available specific tools for controlling various indigenous pests (Zayed 2003). Four isolates of B. bassiana were isolated from Taif region (Saudi Arabia) and genetically identified (Sayed et al. 2018).

The present study aimed to evaluate such isolates against the rose aphid, $M$. rosae, under laboratory and field conditions. The indigenous isolates and a commercial B. bassiana were studied for the aphid control throughout the infestation rates of aphid on Taif's rose. Also, their effect on rose flowers and rose oil yields were evaluated.

\section{Materials and methods}

\section{Fungus isolates and their mass production}

Four genetically different indigenous isolates of $B$. bassiana (Sayed et al. 2018) were used in this study. These isolates were previously isolated from Taif region. Each isolate was cultured twice on potato dextrose agar (PDA) (Acumed, Lansing, USA). Aerial B. bassiana conidia were mass produced in polypropylene bags containing cooked parboiled rice as semi-solid medium ( $100 \mathrm{~g}$ of commercially available rice and $100 \mathrm{ml}$ of distilled water were added to the flask) (Leite et al. 2003). In order to obtain pure conidia, batches of fungus-containing substrate, they were first dehydrated in desiccators containing silica gel for 7 days under room temperature conditions. Subsequently, the colonized substrate was sieved (100 - mesh sieve) under agitation $(250 \mathrm{rpm})$. Then, the harvested conidia were concentrated to $2.3 \times 10^{7}$ spores $/ \mathrm{ml}$ and stored at $4{ }^{\circ} \mathrm{C}$ until used.

\section{Bioassay}

\section{Insects and fungus isolates}

Rose plant leaves infested with rose aphid, $M$. rosae, were collected on the same day of the experiment from the rose field at Taif during March, 2018. Each fungal isolate was prepared as a suspension in five concentrations $\left(1 \times 10^{4}\right.$, $1 \times 10^{5}, 1 \times 10^{6}, 1 \times 10^{7}$, and $1 \times 10^{8}$ spores $\left./ \mathrm{ml}\right)$. Each conidial suspension was vortexed for $5 \mathrm{~min}$ to achieve suspension homogeneity. In order to disperse the conidia uniformly in the suspension, $0.02 \%$ Tween 80 was added (Selvaraj et al. 2012).

\section{Experiment method}

Totally, 100 aphid individuals were used for each concentration (5 replicates, each contained 20 individuals). The bioassay was carried out by dropping $1 \mu \mathrm{l}$ from each concentration directly on the insect body by a micropipette as direct drop application (Eidy et al. 2016). Petri dishes were filled with a thick layer (about $3 \mathrm{~mm}$ ) of $0.1 \%$ agar. Twenty aphid individuals (1 day old) were transferred by a camel hairbrush on rose leaf into each Petri dish. Each aphid adult (in control) was treated with $1 \mu$ of distilled water with Tween $80(0.02 \%)$. Rose fresh leaves were changed daily for feeding aphids. All treatments were maintained at $\left(26 \pm 1{ }^{\circ} \mathrm{C}, 70 \pm 5 \% \mathrm{RH}\right.$ and a photoperiod of $16: 8 \mathrm{~h}$ (L:D)) in an incubator. The aphid individuals were investigated daily for mortality till the 3rd day.

\section{Field applications}

The field experiment was conducted in a rose farm at Alhada, Taif Governorate, Saudi Arabia, by selecting 70$90-\mathrm{cm}$ tall and wide rode plants. These rose plants were pruned at early February 2017. The vegetative and flowering buds appeared by the end of February.

The experimental site was consisted of plots, measuring $4 \mathrm{~m} \times 4 \mathrm{~m}$ and in a randomized complete block design (RCBD). Three meters long space was kept between plots and blocks. Each treatment was replicated three times. Each of the four isolates and the commercial $B$. bassiana (Naturalis ${ }^{\circ}$ ) at the concentration $2.3 \times 10^{7}$ spores $/ \mathrm{ml}$ was applied by two different applications of 0.1 and $0.2 \% \mathrm{v} / \mathrm{v}$ $\left(2.3 \times 10^{6}\right.$ and $4.6 \times 10^{6}$ conidia $/ \mathrm{ml}$, respectively), but the control was treated with water only. A 10-day interval between sprays was adopted with a total of five sprays (from the 3rd of March to the 12th of April), and applications were carried out with a backpack sprayer, equipped with a hollow cone spray nozzle, with a pressure equivalent to $2.88 \mathrm{kgf} / \mathrm{m}^{2}$.

\section{Aphid counts}

The counting of aphids started 10 days after the first spray (3rd of March, 2017). The investigation was carried out on leaves. Randomly, 10 leaves (upper and lower surfaces) from each treated or untreated plant (Control) were 
inspected (Sayed and Montaser 2012). This inspection continued for 10 days after each spray until the last fungus spray (22nd of April, 2017).

\section{Estimation of rose yield}

Numbers of flowers per plant and total weight of flowers in treatment and control plants were estimated by the end of the season.

\section{Extraction of rose oil}

The Soxhlet extraction method was used for obtaining the rose oil. Flowers were filled in a thimble placed in a cylinder. The apparatus was fitted into a flask containing 95\% pure $N$-hexane as a solvent (Moates and Rehynolds 1991). The yield of rose petals of each treatment was used for oil extraction. The flask containing $N$-hexane was heated until boiling. Hexane was vaporized and condensed into thimble. It dissolves the compounds of petals' volatiles. By this way, the organic components were obtained in the flask along with hexane. Then, the oil amounts of each treatment were measured in microliters by a micropipette.

\section{Statistical analysis}

The $\mathrm{LC}_{50}$ value for each isolate was calculated, using Probit analysis with SPSS program (SPSS 2015). The $\mathrm{LC}_{50}$ values, 95\% confidence intervals (lower bound-upper bound), intercept, slope, and chi-square of each isolate were subjected to one-way ANOVA test and means were compared by Duncan's test $(P=0.05)$. In order to correct the mortality data in the treatments with that in the control, Abbott's formula was used (Abbott 1925). The aphid percentage of reduction was analyzed for the five treatments started from day 10 after the first spray. One-way ANOVA was conducted for all parameters, and means were compared by Duncan's test $(P=0.05)$, using SPSS program, version 23 (SPSS 2015).

\section{Results and discussion}

The $\mathrm{LC}_{50}$ values for the four tested indigenous isolates of $B$. bassiana against $M$. rosae after 3 days of treatment are shown in Table 1. The $\mathrm{LC}_{50}$ value of isolate $1\left(6.46 \times 10^{4}\right)$ was significantly higher than the other 3 ones $\left(1.46 \times 10^{5}\right.$,
$1.52 \times 10^{5}$, and $1.71 \times 10^{5}$ for isolates 2,3 , and 4 , respectively) $(F=8.141, P=0.002)$. There were insignificant differences among the lowest bound of 95\% confidence intervals of $\mathrm{LC}_{50}$ values $(F=2.4, \quad P=0.106)$, while these differences were significant in the upper bound $(F=2.863, P=0.03)$. The differences in intercepts, slopes, and $\chi^{2}$ were also insignificant $(F=0.088,0.149$, and 1.734 , $P=0.965,0.929$, and 0.200 , respectively). This result is in correspondence with previous findings of many studies such as of Selvaraj et al. (2012) who found that the $\mathrm{LC}_{50}$ value of $B$. bassiana was $1.5 \times 10^{4}$ spores $/ \mathrm{ml}$ to coriander aphid, Hyadaphis coriandri. Liu et al. (1999) reported that $\mathrm{LC}_{50}$ values for six isolates of $B$. bassiana against $M$. persicae ranged from $1.2 \times 10^{4}$ to $1.55 \times 10^{6}$ spores $/ \mathrm{ml}$. Eidy et al. (2016) recorded $\mathrm{LC}_{50}$ value of $B$. bassiana on $M$. rosae as $2.66 \times 10^{5}$ spores $/ \mathrm{ml}$. Moreover, Saranya et al. (2010) recorded that the $\mathrm{LC}_{50}$ value of $B$. bassiana was $4.5 \times 10^{4}$ spores $/ \mathrm{ml}$ against the aphid, Aphis craccivora adults. Nirmala et al. (2006) revealed that $6.57 \times 10^{5}$ spores $/ \mathrm{ml}$ was the $\mathrm{LC}_{50}$ value for a $B$. bassiana strain against $A$. gossypii nymphs. In this sense, the $\mathrm{LC}_{50}$ values of $B$. bassiana on aphid differed according to the isolate virulence and the host species. For examples, Akmal et al. (2013) found that $\mathrm{LC}_{50}$ values of B. bassiana on the aphids Brevicoryne brassicae and Schizaphis graminum were $6.28 \times 10^{5}$ and $6.76 \times 10^{6}$ spores $/ \mathrm{ml}$, respectively. Moreover, the virulence of various isolates of $B$. bassiana varied against whitefly nymphs on different host plants (Zafar et al. 2016).

Under field experiments, $M$. rosae was the single aphid species recorded on rose plants. The data presented in Table 2 revealed that the aphid's populations in the control increased gradually through the experimental period and provided the highest aphid density values during the last investigation on 22nd of April (32.9 aphid individuals per leaf).

After 10 days of 1 st spray, aphid individuals were significantly decreased on leaves in all treatments (13.57-15.67 aphid individuals per leaf for a concentration of $2.3 \times 10^{6} /$ $\mathrm{ml}$ ) and (6.97-8.7 aphid individuals per leaf for the concentration of $4.6 \times 10^{6} / \mathrm{ml}$ ) comparing to the control (18.67 aphid individuals per leaf). The aphid infestation rates on leaves decreased gradually during the experimental period in all treatments with at commercial and

Table 1 Values of $L_{50}$ with 95\% confidence intervals of the four tested indigenous isolates of Beauveria bassiana on rose aphid, Macrosiphum rosae

\begin{tabular}{|c|c|c|c|c|c|c|}
\hline \multirow[t]{2}{*}{ Isolates } & \multirow{2}{*}{$\begin{array}{l}\mathrm{LC}_{50} \\
\text { (spores/ } \\
\mathrm{ml} \text { ) }\end{array}$} & \multicolumn{2}{|c|}{ 95\% confidence intervals } & \multirow[t]{2}{*}{ Intercept } & \multirow[t]{2}{*}{ Slope \pm SE } & \multirow{2}{*}{$\begin{array}{l}x^{2}(d f \\
=3)\end{array}$} \\
\hline & & Lower bound & Upper bound & & & \\
\hline 1 & $6.46 \times 10^{4 \mathrm{~A}}$ & $3.83 \times 10^{4 \mathrm{~A}}$ & $1.08 \times 10^{5 \mathrm{~A}}$ & $4.0788^{A}$ & $0.853 \pm 0.076^{A}$ & $6.0498^{A}$ \\
\hline 2 & $1.46 \times 10^{5 B}$ & $9.38 \times 10^{4 \mathrm{~A}}$ & $2.20 \times 10^{5 B}$ & $4.1862^{\mathrm{A}}$ & $0.814 \pm 0.077^{A}$ & $4.8008^{\mathrm{A}}$ \\
\hline 3 & $1.52 \times 10^{5 B}$ & $7.53 \times 10^{4 \mathrm{~A}}$ & $3.25 \times 10^{5 B}$ & $4.0524^{\mathrm{A}}$ & $0.784 \pm 0.073^{A}$ & $7.811^{\mathrm{A}}$ \\
\hline 4 & $1.71 \times 10^{5 B}$ & $9.72 \times 10^{4 \mathrm{~A}}$ & $3.31 \times 10^{5 B}$ & $4.2958^{\mathrm{A}}$ & $0.824 \pm 0.067^{\mathrm{A}}$ & $5.8834^{\mathrm{A}}$ \\
\hline
\end{tabular}

Means within each column bearing different letters are significantly different according to the Duncan test $(P=0.05)$ 
Table 2 Population dynamics of aphid, Macrosiphum rosae, on rose plants leaves treated with the four tested indigenous and one commercial Beauveria bassiana

\begin{tabular}{|c|c|c|c|c|c|c|}
\hline \multirow[t]{2}{*}{ Concentrations } & \multirow[t]{2}{*}{ Treatments } & \multicolumn{5}{|c|}{ No. of aphids per leaf (mean \pm SD) } \\
\hline & & 13 Mar. & 23 Mar. & 02 Apr. & 12 Apr. & 22 Apr. \\
\hline \multicolumn{2}{|c|}{ Control (spray with water) } & $18.67 \pm 1.91^{\mathrm{A}}$ & $27.73 \pm 3.40^{\mathrm{A}}$ & $29.70 \pm 3.06^{A}$ & $31.53 \pm 1.70^{\mathrm{A}}$ & $32.90 \pm 3.61^{\mathrm{A}}$ \\
\hline \multirow{5}{*}{$\begin{array}{l}0.1 \% \mathrm{v} / \mathrm{v} \\
\left(2.3 \times 10^{6} / \mathrm{ml}\right)\end{array}$} & Naturalis & $13.57 \pm 1.37^{B}$ & $12.47 \pm 1.10^{B}$ & $9.33 \pm 0.71^{B}$ & $6.83 \pm 1.01^{B}$ & $6.50 \pm 0.87^{B}$ \\
\hline & Isolate 1 & $15.67 \pm 1.72^{A B}$ & $11.77 \pm 2.10^{B}$ & $10.53 \pm 2.47^{B}$ & $8.70 \pm 2.19^{B}$ & $9.17 \pm 2.35^{B}$ \\
\hline & Isolate 2 & $15.40 \pm 1.80^{\mathrm{AB}}$ & $12.23 \pm 1.40^{B}$ & $11.33 \pm 2.35^{B}$ & $8.63 \pm 1.90^{B}$ & $8.00 \pm 1.25^{B}$ \\
\hline & Isolate 3 & $13.63 \pm 1.80^{B}$ & $13.00 \pm 3.00^{\mathrm{B}}$ & $9.73 \pm 2.95^{B}$ & $8.73 \pm 1.72^{\mathrm{B}}$ & $7.40 \pm 1.73^{B}$ \\
\hline & Isolate 4 & $13.87 \pm 2.28^{\mathrm{B}}$ & $12.57 \pm 3.27^{B}$ & $9.70 \pm 1.50^{B}$ & $9.37 \pm 2.00^{B}$ & $7.40 \pm 1.95^{B}$ \\
\hline \multirow{5}{*}{$\begin{array}{l}0.2 \% \mathrm{v} / \mathrm{v} \\
\left(4.6 \times 10^{6} / \mathrm{ml}\right)\end{array}$} & Naturalis & $7.30 \pm 1.78^{C}$ & $4.60 \pm 0.75^{c}$ & $2.43 \pm 0.70^{C}$ & $1.17 \pm 1.07^{C}$ & $0.47 \pm 0.42^{c}$ \\
\hline & Isolate 1 & $7.73 \pm 2.55^{C}$ & $4.97 \pm 1.10^{C}$ & $2.50 \pm 1.25^{C}$ & $1.37 \pm 1.35^{C}$ & $0.83 \pm 0.42^{c}$ \\
\hline & Isolate 2 & $8.70 \pm 2.82^{C}$ & $4.70 \pm 1.25^{C}$ & $2.63 \pm 0.35^{c}$ & $1.50 \pm 1.37^{C}$ & $0.47 \pm 0.57^{C}$ \\
\hline & Isolate 3 & $7.70 \pm 2.13^{C}$ & $5.00 \pm 1.73^{C}$ & $3.13 \pm 1.96^{C}$ & $1.07 \pm 1.05^{C}$ & $0.67 \pm 0.61^{c}$ \\
\hline & Isolate 4 & $6.97 \pm 2.31^{c}$ & $3.87 \pm 1.17^{C}$ & $2.97 \pm 1.16^{C}$ & $1.07 \pm 0.57^{C}$ & $0.60 \pm 1.04^{C}$ \\
\hline \multicolumn{2}{|l|}{$F$ values } & 11.930 & 34.582 & 52.370 & 100.884 & 97.629 \\
\hline \multicolumn{2}{|l|}{$P$} & $<0.001$ & $<0.001$ & $<0.001$ & $<0.001$ & $<0.001$ \\
\hline
\end{tabular}

Means within each column bearing different letters are significantly different according to the Duncan test $(P=0.05)$

indigenous $B$. bassiana but this decrease was slightly observed at the low fungal concentration (Table 2).

Regarding the percent aphid reduction, these values varied and significantly influenced according to the fungus concentration and the investigation time (Table 3). This percentage differed significantly between the two-tested concentrations in all the investigated times but there are no significant differences among all isolates with the same concentration except for the lower concentration on the 22nd of April. After three sprays in the present study, the aphid reduction percentages reached $(<90 \%)$ with the highest concentration but this ratio was not reached by the lowest concentration even at the end of the experiment. In addition, this value $(<95 \%)$ was achieved after four sprays with the highest concentration (Table 3). In general, different applications were carried out to investigate the efficacy of various isolates of $B$. bassiana for controlling various species of aphids on different crops (Michereff et al. 2011 and Ujjan and Shahzad 2012). Obtained results revealed that the aphid population in the control increased gradually through the experimental period and gave the highest aphid density values during April. This finding coincides with the results of Sayed and Montaser (2012) who found that the numbers of aphid individuals of $M$. rosae in untreated rose plants during the experiment ranged from 34.75 to 47.1 individuals/leaf.

Table 3 Aphid percentage reduction of aphid, Macrosiphum rosae, on rose plants leaves treated with the four tested indigenous and one commercial Beauveria bassiana

\begin{tabular}{|c|c|c|c|c|c|c|}
\hline \multirow[t]{2}{*}{ Concentrations } & \multirow[t]{2}{*}{ Treatments } & \multicolumn{5}{|c|}{ Aphid percentage reduction (mean \pm SD) } \\
\hline & & 13 Mar. & 23 Mar. & 02 Apr. & 12 Apr. & 22 Apr. \\
\hline \multirow{5}{*}{$\begin{array}{l}0.1 \% \mathrm{v} / \mathrm{V} \\
\left(2.3 \times 10^{6} / \mathrm{ml}\right)\end{array}$} & Naturalis & $27.32 \pm 7.32^{\mathrm{A}}$ & $55.05 \pm 3.97^{\mathrm{A}}$ & $68.57 \pm 2.39^{\mathrm{A}}$ & $78.33 \pm 3.19^{\mathrm{A}}$ & $80.24 \pm 2.65^{\mathrm{A}}$ \\
\hline & Isolate 1 & $16.07 \pm 9.23^{\mathrm{A}}$ & $57.57 \pm 7.57^{\mathrm{A}}$ & $64.53 \pm 8.32^{\mathrm{A}}$ & $72.41 \pm 6.95^{\mathrm{A}}$ & $72.14 \pm 7.13^{B}$ \\
\hline & Isolate 2 & $17.50 \pm 9.66^{\mathrm{A}}$ & $55.89 \pm 5.05^{\mathrm{A}}$ & $61.84 \pm 7.90^{\mathrm{A}}$ & $72.62 \pm 6.04^{A}$ & $75.68 \pm 3.79^{\mathrm{AB}}$ \\
\hline & Isolate 3 & $26.97 \pm 9.65^{\mathrm{A}}$ & $53.13 \pm 10.83^{A}$ & $67.23 \pm 9.93^{\mathrm{A}}$ & $72.31 \pm 5.44^{\mathrm{A}}$ & $77.51 \pm 5.27^{\mathrm{AB}}$ \\
\hline & Isolate 4 & $25.72 \pm 12.22^{\mathrm{A}}$ & $54.69 \pm 11.81^{\mathrm{A}}$ & $67.34 \pm 5.05^{\mathrm{A}}$ & $70.30 \pm 6.34^{\mathrm{A}}$ & $77.51 \pm 5.92^{\mathrm{AB}}$ \\
\hline \multirow{5}{*}{$\begin{array}{l}0.2 \% \mathrm{v} / \mathrm{v} \\
\left(4.6 \times 10^{6} / \mathrm{ml}\right)\end{array}$} & Naturalis & $60.89 \pm 9.52^{B}$ & $83.41 \pm 2.72^{B}$ & $91.81 \pm 2.37^{B}$ & $96.30 \pm 3.39^{B}$ & $98.58 \pm 1.26^{C}$ \\
\hline & Isolate 1 & $58.57 \pm 13.68^{B}$ & $82.09 \pm 3.98^{B}$ & $91.58 \pm 4.20^{B}$ & $95.67 \pm 4.28^{B}$ & $97.47 \pm 1.26^{c}$ \\
\hline & Isolate 2 & $53.39 \pm 15.08^{B}$ & $83.05 \pm 4.51^{B}$ & $91.14 \pm 1.18^{B}$ & $95.24 \pm 4.36^{B}$ & $98.58 \pm 1.73^{C}$ \\
\hline & Isolate 3 & $58.75 \pm 11.40^{B}$ & $81.97 \pm 6.25^{B}$ & $89.45 \pm 6.60^{B}$ & $96.62 \pm 3.33^{B}$ & $97.97 \pm 1.86^{C}$ \\
\hline & Isolate 4 & $62.68 \pm 12.39^{B}$ & $86.06 \pm 4.21^{B}$ & $90.01 \pm 3.90^{B}$ & $96.62 \pm 1.80^{B}$ & $98.18 \pm 3.16^{C}$ \\
\hline F values & & 9.062 & 14.543 & 15.294 & 19.716 & 25.781 \\
\hline$P$ & & $<0.001$ & $<0.001$ & $<0.001$ & $<0.001$ & $<0.001$ \\
\hline
\end{tabular}

Means within each column bearing different letters are significantly different according to Duncan test $(P=0.05)$ 
The same observation was recorded in the study of Sayed and Alghamdi (2017).

The results showed that both commercial and indigenous isolates were effective against rose aphid. Filho et al. (2011) demonstrated that the numbers of adults and nymphs of $M$. persicae per leaf were significantly reduced in plots treated with two $B$. bassiana isolates ranging from 57 to $60 \%$. Further field studies using screened cages with isolate CG 864 (formulated as oil dispersion) reduced the population of aphids by $85-87 \%$ than the untreated plants, while a reduction of $71 \%$ was demonstrated in the plants treated with the aqueous conidial suspension, 20 days after the first spray. Furthermore, in a commercial cabbage field (without cages), the fungus was sprayed at three different times, each with an equivalent of $1 \times 10^{13}$ viable conidia per ha. In this experiment, the aphid reduction per leaf was the most evident between 4th and 5th weeks after the first spray, resulting in $76-83 \%$ and $57-65 \%$ control for unformulated conidia and oil dispersions, respectively. Generally, B. bassiana as an EPF is effective on various sucking insect pests (Dara 2017). Different investigations stated that $B$. bassiana showed high efficacies for controlling different aphid species such as Aphis craccivora Koch. infesting cucumber plants (Zaki 1998) and the cabbage aphid Brevicoryne brassicae (Pacheco et al. 2017). Moreover, Murphy et al. (1998) used B. bassiana to control the western flower thrips (WFT) on commercial roses and stated that significantly fewer WFT were detected in the B. bassiana ES plots than in the untreated (control) plots. Obtained results indicated that the aphid reductions, with a concentration of $4.6 \times 10^{6}$ conidia/ml were about $98 \%$ for all indigenous and commercial isolates. Loureiro and Moino (2006) found that B. bassiana applied at $10^{6}$ spores/ $\mathrm{ml}$ caused $100 \%$ mortality in the aphid M. persicae while Ramegowda et al. (2007) recorded that 93.33\% mortality was achieved on sugarcane woolly aphid, Ceratovacuna lanigera, after 10 days of treatment.

The data presented in Table 4 represent the effect of the four indigenous and one commercial B. bassiana on rose plant flowers' formation and oil yield. Number of flowers per plant was not affected by these applications. It ranged between 756 and 885 flowers per plant. The weight of flowers per plant was significantly differed between the control and the highest concentration of all tested isolates but with insignificant differences between the control and the lowest concentration of all tested isolates. The current findings revealed that the amount of oil extracted from flowers per plant was highly affected by these applications. But among the same concentration treatments, there were insignificant differences. The findings coincide with previous results on quantification of lipids in the rose inflorescence as its level was significantly lowered in highly infested plants with aphids relative to lower aphid infested plants (Singh et al. 2014). In general, due to the infestation of aphids on rose plants, the biochemical composition of plant was affected (Singh et al. 2014). Teulon et al. (1999) reported a high reduction in the value of the medicinal components of the plant and economic loss to growers due to the infestation of insect pests, especially aphids during spring and summer seasons. Moreover, applications of effective control strategies of various pests and diseases especially biocontrol agents under organic management practices in rose production are very important for the production of high flower yields and also the oil quality (Chalova et al. 2017). Virulence of the four tested indigenous isolates in the bioassay indicated that one isolate was higher in its efficacy with lower $\mathrm{LC}_{50}$ value than

Table 4 Application effect of the four tested indigenous and one commercial Beauveria bassiana on production of rose plants

\begin{tabular}{|c|c|c|c|c|}
\hline Concentrations & Treatments & $\begin{array}{l}\text { No. of flower/plant (mean } \pm \\
\text { SD) }\end{array}$ & $\begin{array}{l}\text { Weight of flower/plant (gm) (mean } \pm \\
\text { SD) }\end{array}$ & $\begin{array}{l}\text { Oil amount/plant (microliter) (mean } \pm \\
\text { SD) }\end{array}$ \\
\hline \multicolumn{2}{|c|}{ Control (spray with water) } & $756.33 \pm 87.05^{\mathrm{A}}$ & $773.00 \pm 60.75^{\mathrm{A}}$ & $565.00 \pm 66.01^{A}$ \\
\hline \multirow{5}{*}{$\begin{array}{l}0.1 \% v / v\left(2.3 \times 10^{6} /\right. \\
\mathrm{ml})\end{array}$} & Naturalis & $819.33 \pm 33.29^{A}$ & $931.67 \pm 64.93^{A B}$ & $728.67 \pm 74.23^{B}$ \\
\hline & Isolate 1 & $796.00 \pm 80.52^{\mathrm{A}}$ & $949.67 \pm 115.98^{\mathrm{AB}}$ & $706.67 \pm 49.36^{B}$ \\
\hline & Isolate 2 & $752.67 \pm 113.68^{A}$ & $920.67 \pm 159.36^{\mathrm{AB}}$ & $721.67 \pm 63.71^{B}$ \\
\hline & Isolate 3 & $843.00 \pm 61.02^{\mathrm{A}}$ & $947.33 \pm 153.51^{\mathrm{AB}}$ & $724.00 \pm 31.24^{B}$ \\
\hline & Isolate 4 & $803.67 \pm 59.41^{\mathrm{A}}$ & $893.33 \pm 71.74^{\mathrm{AB}}$ & $692.00 \pm 20.66^{B}$ \\
\hline \multirow{5}{*}{$\begin{array}{l}0.2 \% v / v\left(4.6 \times 10^{6} /\right. \\
\mathrm{ml})\end{array}$} & Naturalis & $813.67 \pm 105.40^{\mathrm{A}}$ & $998.67 \pm 105.19^{B}$ & $855.33 \pm 41.40^{C}$ \\
\hline & Isolate 1 & $825.33 \pm 90.63^{A}$ & $988.00 \pm 98.96^{B}$ & $826.00 \pm 51.26^{c}$ \\
\hline & Isolate 2 & $885.67 \pm 27.75^{\mathrm{A}}$ & $1006.00 \pm 34.00^{B}$ & $876.33 \pm 55.18^{C}$ \\
\hline & Isolate 3 & $803.67 \pm 73.92^{A}$ & $978.00 \pm 108.59^{B}$ & $816.67 \pm 56.15^{c}$ \\
\hline & Isolate 4 & $783.67 \pm 25.15^{\mathrm{A}}$ & $1012.33 \pm 95.97^{B}$ & $853.33 \pm 26.10^{c}$ \\
\hline \multicolumn{2}{|l|}{$F$ values } & 0.763 & 1.312 & 10.035 \\
\hline \multicolumn{2}{|l|}{$P$} & 0.662 & 0.284 & $<0.001$ \\
\hline
\end{tabular}

Means within each column bearing different letters are significantly different according to the Duncan test $(P=0.05)$ 
the other three isolates while all four isolates approximately had the same effect on aphid reduction in the field. This difference in efficacy between laboratory and field assessment might be due to the effect of the environmental conditions under which the tests were carried out.

\section{Conclusions}

In conclusion, the concentration $4.6 \times 10^{6}$ conidia/ml of the commercial or indigenous isolates achieved higher reductions of $M$. rosae infestation on rose plants and resulted in the highest extraction of rose oil. Moreover, the use of B. bassiana could participate in organic production of rose and prevent the pollution with chemical pesticides in rose oil. Therefore, using the indigenous isolates of $B$. bassiana for controlling aphids on rose plants is recommended. Further studies on the efficacy of the EPF under field conditions are still needed.

\section{Acknowledgements}

The authors would like to express their deepest thanks to KACST, Saudi Arabia, for the financial support for the current research through a research grant number: SG-36-95.

\section{Funding}

This work was financially supported by KACST, Saudi Arabia.

\section{Availability of data and materials}

The datasets generated and analyzed during the current study are available in the text.

\section{Authors' contributions}

All authors read and approved the final manuscript.

\section{Ethics approval and consent to participate}

Not applicable.

\section{Consent for publication}

This study does not contain any individual person's data.

\section{Competing interests}

The authors declare that they have no competing interests.

\section{Publisher's Note}

Springer Nature remains neutral with regard to jurisdictional claims in published maps and institutional affiliations.

Received: 4 January 2019 Accepted: 15 March 2019

Published online: 02 April 2019

\section{References}

Abbott WS (1925) A method of computing the effectiveness of an insecticide. J Econ Entomol 18:265-267

Akmal M, Freed SH, Malik MN, Gul HT (2013) Efficacy of Beauveria bassiana (Deuteromycotina: Hypomycetes) against different aphid species under laboratory conditions. J Zool 45(1):71-78

Amatuzzi RF, Cardoso N, Poltronieri AS, Poitevi, CG, Dalzoto P, Zawadeneak MA, Pimentel IC (2017) Potential of endophytic fungi as biocontrol agents of Duponchelia fovealis (Zeller) (Lepidoptera: Crambidae). Braz J Biol, Epub November 09: 2017. https://doi.org/10.1590/1519-6984.166681

Chalova VI, Manolov IG, Manolova VS (2017) Challenges for commercial organic production of oil-bearing rose in Bulgaria. Biol Agric Hortic 33(3):183-194

Chau A, Heinz KM (2004) Biological control of aphids on ornamental crops. In: Heinz KM, van Driesche RG, Parrella MP (eds) Biocontrol in protected culture. Ball publishing, Batavia, pp 277-295
Dara SK (2017) Biology and management of sucking pests of canola. Integrated management of insect pests on canola and other Brassica oilseed crops. Reddy G. CABI 68-76

Eidy M, Dastjerdi HR, Zargarzadeh F, Golizadeh A, Mahdavi V (2016) Pathogenicity of the Entomopathogenic Fungi Beauveria bassiana (Balsamo) and Verticillium lecanii (Zimmerman) against aphid Macrosiphum rosae, Linnaeus (Hemiptera: Aphididae) under laboratory conditions. Jordan J Biol Sci 9(1):25-29

Filho MM, Oliveira SOD, De Liz RS, Faria M (2011) Cage and field assessments of Beauveria bassiana-based Mycoinsecticides for Myzus persicae Sulzer (Hemiptera: Aphididae) control in cabbage. Neotrop Entomol 40:470-476

Inglis DG, Goettel MS, Butt TM, Strasser H (2001) Use of hyphomycetous fungi for managing insect pests. In: Butt TM, Jackson C, Magan N (eds) Fungi as biocontrol agents: Progress, problems, and potential. CAB International, Wallingford, pp 23-69

Karlik JF, Tjosvold SA (2003) Integrated pest management (IPM) for roses. In: Roberts AV (ed) Encyclopedia of rose science. Elsevier Science, Amsterdam

Leite LG, Batista FA, Almeida JEM, Alves SB (2003) Produção de fungos entomopatogênicos. Ribeirão Preto, Pinto AS, 92p

Liu YQ, Liu SS, Feng MG (1999) Effect of Beauveria bassiana on the fecundity of the green peach aphid, Myzus persicae. Acta Phytophylacica Sin 26(1):30-34

Loureiro EDS, Moino JA (2006) Pathogenicity of hyphomycete fungi to aphids Aphis gossypii Glover and Myzus persicae (Sulzer) (Hemiptera: Aphididae). Neotrop Entomol 35(5):660-665

Martins ICF, Silva RJ, Alencar JRDCC, Silva KP, Cividanes FJ, Duarte RT, Agostini LT, Polanczy RA (2014) Interactions between the entomopathogenic fungi Beauveria bassiana (Ascomycota: Hypocreales) and the aphid parasitoid Diaeretiella rapae (Hymenoptera: Braconidae) on Myzus persicae (Hemiptera: Aphididae). J Econ Entomol 107(3):933-938

Michereff M, Oliveira S, de Liz RS, Faria M (2011) Cage and field assessments of Beauveria bassiana-based Mycoinsecticides for Myzus persicae Suizer (Hemiptera: Aphididae) control in cabbage. Neotrop Entomol 40(4):470-476

Moates GK, Rehynolds J (1991) Comparison of rose extract produced by different extraction techniques. J Essential Oil Res 4:289

Murphy BC, Morisawa TA, Newman JP, Tjosvold ST, Parrella MP (1998) Fungal pathogen controls thrips in greenhouse flowers. Calif Agric 52:32-36

Nirmala R, Ramanujan B, Rabindra RJ, Rao NS (2006) Effect of entomofungal pathogens on mortality of three aphid species. J Biol Control 20:89-94

Pacheco JC, Poltronieri AS, Porsani MV, Zawadneak MAC, Pimentel IC (2017) Entomopathogenic potential of fungi isolated from intertidal environments against the cabbage aphid, Brevicoryne brassicae (Hemiptera: aphididae). Biocontrol Sci Techn 25(4):496-509

Ramegowda GK, Vidya M, Patil RK, Puttannavar MS, Lingappa S (2007) Laboratory and field evaluation of some entomopathogenic fungi against sugarcane woolly aphid, Ceratovacuna lanigera Zehntner (Homoptera: Aphididae). J Biol Control 21:173-176

Saranya S, Ushakumari R, Jacob S, Philip BM (2010) Efficacy of different entomopathogenic fungi against cowpea aphid, Aphis craccivora (Koch). J Biopest 3(1):138-142

Sayed SM, Alghamdi A (2017) Field evaluation of two indigenous coccinellids species released for controlling the rose aphid, Macrosiphum rosae (L.) on rose plants. Egypt J Biol Pest Control 27(2):217-221

Sayed SM, Ali EF, El-Arnaouty SA, Mahmoud SF, Amer SA (2018) Isolation, identification and molecular diversity of indigenous isolates of Beauveria bassiana from Taif region, Suadi Arabia. Egypt J Biol Pest Control 28:47 6

Sayed SM, Montaser MM (2012) Preliminary molecular characterization and utilization of native Orius sp. (Hemiptera: Anthocoridae) for controlling aphids infesting taif's rose. Arch Phytopathol Plant Protec 45(3):373-380

Seiedy M, Heydari S, Tork M (2015) Orientation of Hippodamia variegata (Coleoptera: Coccinellidae) to healthy and Beauveria bassiana-infected Aphis fabae (Hemiptera: Aphididae) in an olfactometer system. Turk J Zool 39:53-58

Selvaraj K, kaushik HD, Gulati R (2012) Evaluation of Beauveria bassiana (Balsamo) Vuillemin against coriander aphid, Hyadaphis coriandri (Das) (Aphididae: Homoptera). J Biol Control 26(1):55-58

Singh P, Dhal MK, Sagar SK (2014) Experimental investigation on nutritional variation in plant foliage of rose (Rosa damascene): effect of pest infestation. Int J Sci Res Publication 4(5):1-12

SPSS (2015) IBM SPSS Statistics for Windows (Version 23.0). IBM Corp, Armonk Chicago, IL

Tanada Y, Kaya HK (1993) Insect pathology. Academic Press, London 
Teulon DAJ, Eastop VF, Stufkens MAW, Harcourt SJ (1999) Illustrated multiple entry key for apterous aphids of economic importance in New Zealand. Crop Info Confidential Report No. 612.Crop and Food Research, Lincoln, New Zealand Pp 140

Ujjan AA, Shahzad S (2012) Use of entomopathogenic fungi for the control of mustard aphids (Lipaphi serysimi) on canola (Brassica napus L.). Pak J Bot 44:2081-2086

Zafar J, Freed S, Khan BA, Farooq M (2016) Effectiveness of Beauveria bassiana against cotton whitefly, Bemisia tabaci (Gennadius) (Aleyrodidae: Homoptera) on different host plants. Pak J Zool 48(1):91-99

Zaki FN (1998) Efficiency of the entomopathogenic fungus, Beauveria bassiana (Bals), against Aphis craccivora Koch and Bemesia tabaci, Gennandius. J Econ Entomol 122(1-5):397-399

Zayed A (2003) Pathogenecity of two Beauveria bassiana indigenous isolates towards the greater wax moth Galleria mellonella L. larvae in Egypt.

Efflatounia 3:10-14

\section{Submit your manuscript to a SpringerOpen ${ }^{\circ}$ journal and benefit from:}

- Convenient online submission

- Rigorous peer review

- Open access: articles freely available online

- High visibility within the field

- Retaining the copyright to your article

Submit your next manuscript at $\boldsymbol{\wedge}$ springeropen.com 